College Tutor, and P. MBAYA, College Tutor, Central Manchester Healthcare NHS Trust, Psychiatry Directorate, York House, Old Age Service, York Place, Oxford Road, Manchester M13 9WL

Sir: For many years the College has published a list of successful candidates for both parts of the Examination by posting a pass list on noticeboards at the College in London and at its divisional offices in Edinburgh, Dublin and Cardiff. Dr Allen et al are certainly not alone in producing convincing arguments as to why this is not satisfactory for trainees or College tutors, and particularly for those located some distance from the College's offices.

I have been very keen, since my appointment a year ago, to develop the use of the College website to widen access to information about the examination regulations and syllabus, the application process and the publication of results. I am very pleased to report that all of this information is now available on the College website, and from Autumn 1999 the MRCPsych Examination pass lists will also be published on the website on the same day that results are posted to candidates. The results will continue to be displayed in the College and its divisional offices for those who find this the most convenient point of access.

I am aware that there are further developments which should be possible in our use of the Internet, but I hope that you will find what has been achieved so far as a major improvement in the service we provide.

JULIE SMALLS, Head of Examination Services, Royal College of Psychiatrists, 17 Belgrave Square, London SWIX 8PG

\section{Comments on psycho-oncology}

Sir: Montgomery (Psychiatric Bulletin. July 1999, 23, 431-435) has written a comprehensive and useful summary of the recent development, present state and future challenges of psychooncology. I wish to make just three comments.

In a recent study by Watson et al (1999) of 578 patients with early breast cancer, the association found by Greer (1979, 1990) between fighting spirit and a longer period of survival was not confirmed, although the association between depressive symptoms (as measured on the Hospital Anxiety and Depression Scale) and worse survival was. This is an important finding given the significance attributed to fighting spirit by many patients and their resultant anxiety if they think they do not have, but should have fighting spirit.

Montgomery mentions Spiegel et als (1989) finding that metastatic breast cancer patients randomly assigned to receive group therapy lived on average 18 months longer than the control patients. This has been challenged by Fox (1998) who pointed out that the treatment group did only as well as the national and local average while the control group died at a faster than average rate. This suggests a sampling error and casts doubt on the supposed positive effect on survival of this type of treatment.

A major problem for psycho-oncology remains the low esteem in which psychological treatments are held by oncologists and cancer surgeons. Underlying this is a dilapidated Cartesian dualism, that is the view that mind and body are two very different substances, so different in fact that an interaction between the two can hardly even be conceptualised. Psychooncologists, for their part, have failed to suggest an alternative model - or even to show any interest in the problem.

\section{References}

Fox, B. (1998) A hypothesis about Spiegel et afs 1989 paper on psychosocial intervention and breast cancer survival. Psycho-Oncology. 7. 361-370.

Greer, S., MORRIS, T. \& Pettingnle, K. W. (1979) Psychological response to breast cancer: effect on outcome. Lancet, 2, 785-787.

- - - - - et al (1990) Psychological response to breast cancer and 15-year outcome. Lancet, 1, 49-50.

SPIEGEL, D., BLOOM, J. R., KRAEMER, H. C., et al (1989) Effect of psychosocial treatment on survival of patients with metastatic breast cancer. Lancet, 2, 888-891.

PAUL CRICHTON, Consultant Psychiatrist and Senior Lecturer, Royal Marsden Hospital, Fulham Road, London SW3 6JJ

\section{Stigmatisation of peychiatric disorder}

Sir: Stephen Lawrie (Psychiatric Bulletin, March $1999,23,129-131)$ described many of the effects of stigmatisation in people suffering from psychiatric disorders. I would like to add another dimension; the discrimination of psychiatric patients in obtaining adequate physical care.

As a registrar, I was once asked to see a known patient, suffering from schizophrenia and thearing voices' in casualty. I asked what had brought him into hospital and he described a severe chest pain. I checked the casualty card on which was simply written "hearing voices $\rightarrow$ refer psyche". After further investigation, it became apparent that his only concern was his chest pain and that the hallucinations were incidental, chronic and not bothering him in any way. No physical examination or electrocardiogram had been 
attempted, so I asked the casualty officer if the patient had indeed complained of chest pain on admission. "Yes" was the reply, "but he was also hearing voices"!

With up to $80 \%$ of psychiatric patients suffering from physical illness (Hall et al, 1981), this example highlights the great need for adequate training and education, especially at medical school, if discrimination and stigma are to be reduced.

\section{Reference}

HALL, R. C. W. GARDNER, E. R. POPKIN, M. K, et al (1981) Unrecognised physical lliness prompting psychiatric admission: a prospective study. American Joumal of Psychiatry, 188, 629-635.

ANITA KOTAK, Senior Registrar, Park Royal Hospital for Mental Health, Acton Lane, London NW10 7NS

\section{Writing to patients}

Sir: In his editorial entitled 'Writing to patients' Marios Pierides (Psychiatric Bulletin, July 1999, 23, 385-386) says that "There have been no published data on the effects of writing to psychiatric patients". This is not true. In the 1980s the Department of Psychiatry at Milton Keynes carried out a randomised study of writing to the patient after an initial out-patient consultation compared with the usual procedure of writing to the general practitioner. Outcomes in terms of satisfaction, comprehension and adherence with treatment were assessed by a clinical psychologist. Patients who received a letter were significantly more satisfied than patients who did not (Asch et al, 1991) and this was confirmed by their comments on the procedure (Price \& Asch, 1990). It was suggested that writing to patients should become part of medical education (Price, 1993) to supplement other training in communication skills.

The possibility of writing directly to psychiatric out-patients was also addressed by Thomas (1998), who found that, with the exception of patients with schizophrenia, there was considerable interest in receiving a letter. This confirms our experience in Milton Keynes in which the small number of patients with psychosis did not respond favourably to the letter, whereas the great majority of patients without psychosis were enthusiastic - some of them commented: "Why can't all doctors do this?"

\section{References}

Asch, R., Price, J. \& Hawks, G. (1991) Psychiatric outpatients' reactions to summary letters of their consultations. British Journal of Medical Psychology. 64, 3-9.

PRICE, J. S. (1993) Teaching communication skills. British Medical Journal, s07, 130.

- \& ASCH. R. (1990) Writing to the patient. Comments of patients who received a letter following an initial outpatient consultation. Psychiatric Bulletin, 14, 467-469.

Thomas, P. (1998) Writing letters to patients. Psychiatric Bulletin, 22, 542-545.

JOHN PRICE, Locum Consultant Psychiatrist, Mill View Hospital, Brighton BN3 $7 \mathrm{HZ}$ 